\title{
Glucosinolate biosynthesis as influenced by growth media and auxin in hairy root cultures of kale (Brassica oleracea var. acephala)
}

\author{
Sook Young Lee1, Sun Ju Bong², Jae Kwang Kim, Sang Un Park²* \\ ${ }^{1}$ Regional Innovation Center for Dental Science \& Engineering, Chosun University, 309 Pilmun-daero, Dong-gu, Gwangju, 501-759, Korea, \\ ${ }^{2}$ Department of Crop Science, Chungnam National University, 99 Daehak-Ro, Yuseong-gu, Daejeon 305-764, Kore, ${ }^{3}$ Division of Life Sciences \\ and Bio-Resource and Environmental Center, Incheon National University, Incheon 406-772, Korea
}

\section{A B S T R A C T}

\begin{abstract}
This study aimed to investigate the effects of various growth media and three types of auxins on glucosinolate biosynthesis in hairy root cultures of kale (Brassica oleracea var. acephala). Four different glucosinolates (4-hydroxyglucobrassicin, glucobrassicin, 4-methoxyglucobrassicin, and neoglucobrassicin) were used in this study. The accumulation of glucosinolates was influenced by both media and auxin treatments. Of the media treatments, full-strength Gamborg's B5 medium (B5) supported the highest accumulation of total glucosinolates, followed by full-strength Murashige-Skoog medium (MS), whereas the lowest glucosinolates accumulation was in the half-strength MS medium treatment. The accumulation of glucobrassicin was very high, followed by 4-methoxyglucobrassicin, irrespective of the growth medium used. The highest content of glucobrassicin was measured in cultures in B5 medium, while MS medium resulted in the highest accumulation of 4-methoxyglucobrassicin. Half-strength B5 medium resulted in the highest content of neoglucobrassicin, and Schenk and Hildebrandt medium (SH) supported the highest content of 4-hydroxyglucobrassicin. The total and individual levels of glucosinolates in hairy root cultures of kale were all influenced by exposure to the nine auxin treatments, with the exception glucobrassicin. In general, levels of glucosinolate decreased with increasing concentrations of auxins. Treatment with the auxin indole-3-butyric acid (IBA) 0.1 resulted in the highest total concentration of glucosinolates, measuring 1.83 times higher than that of hairy root cultures treated with naphthalene acetic acid (NAA) 1.0, which resulted in the lowest glucosinolate concentrations. Of the four glucosinolates, glucobrassicin and 4-methoxyglucobrassicin contents were considerably higher. The auxin IBA 0.1 promoted the highest 4-methoxyglucobrassicin accumulation in the hairy root cultures of kale. The auxin treatment indole-3-acetic acid (IAA) 0.1 resulted in the highest amount of 4-hydroxyglucobrassicin and neoglucobrassicin. Hairy root cultures could be a valuable alternative approach for the production of glucosinolate compounds from kale.
\end{abstract}

Keywords: Glucosinolates; Growth; Media; Auxin; Hairy Root; Kale

\section{INTRODUCTION}

The genus Brassica is one of the core genera of the tribe Brassicaceae and includes many economically important species that are distributed in a variety of agro-climatic regions worldwide. Plants belonging to the family Brassicaceae have been recognized as an important component of healthy diets because of their high contents of vitamin C, vitamin A, folic acid, dietary fiber, minerals, and bioactive phytochemicals-especially glucosinolates (GSLs) (Baenas et al., 2012; De Nicola et al., 2013). According to recent epidemiological studies, the intake of cruciferous vegetables containing glucosinolates and potential chemopreventive agents, such as Chinese cabbage, cabbage, radish, kale, turnip, watercress, cauliflower, broccoli, and Brussels sprouts, plays an important role in antioxidant defenses and cancer prevention (Conaway et al., 2002). Many of the health benefits of kale are well supported. Kale (Brassica oleracea var. acephala) is among the most healthy and nutrient-dense foods on the planet and is considered the healthiest of all the leafy green vegetables. Kale has a very high content of beneficial compounds, some of which have been shown to have powerful medicinal properties. Kale also contains high concentrations of antioxidants, vitamin $\mathrm{C}$ and vitamin $\mathrm{K}$, substances of lowering cholesterol, cancer-fighting

\footnotetext{
${ }^{*}$ Corresponding author:

Dr. Jae Kwang Kim, Division of Life Sciences and Bio-Resource and Environmental Center, Incheon National University, Incheon 406-772, Korea. E-mail: kjkpj@inu.ac.kr; Tel.: +82-32-835-8241; Fax: +82-32-835-0763.

Dr. Sang Un Park, Department of Crop Science, Chungnam National University, 99 Daehak-Ro, Yuseong-gu, Daejeon 305-764, Korea. E-mail: supark@cnu.ac.kr; Tel.: +82-42-821-6730; Fax: +82-42-822-2631.

Received: 20 January 2016; Revised: 22 February 2016; Accepted: 23 February 2016; Published Online: 12 March 2016
} 
substances, beta-carotene content, minerals, carotenoids like lutein and zeaxanthin (Kim et al., 2008; Sikora and Bodziarczyk, 2012; Migliozzi et al., 2015; Walsh et al., 2015; Groenbaek et al., 2016).

Approximately 200 different glucosinolates are known to occur naturally in plants (Clarke, 2010; Jørgensen et al., 2015). Glucosinolates are hydrolyzed into many bioactive compounds by the endogenous enzyme myrosinase ( $\beta$-thi oglucosidaseglucohydrolase) (EC 3.2.3.1). The products of glucosinolate hydrolysis include substituted isothiocyanates, nitriles, thiocyanates, epithionitriles, and oxazolidinethiones, which play roles in defense and have various biological activities related to human health (Al-Gendy et al., 2010; Björkman et al., 2011). Glucosinolates from vegetables of the family Brassicaceae are also associated with reduced risks of cancers of the lungs, stomach, breasts, prostate, pancreas, colon, and rectum (Herr and Büchler, 2010; Krzyzanowska et al., 2011).

Hairy root disease is caused by infection with Agrobacterium rhizogenes, a naturally occurring soil bacterium. Hairy roots have rapid growth potential and show unlimited growth increase in media in the absence of growth hormones, such as auxin (Park et al., 2014). In addition, hairy root cultures from several important plant species produce the same or higher amounts of secondary metabolites compared to those produced by the parent plants (Zhi-Bi and Min. 2006). The production of secondary metabolites in hairy root cultures is influenced by many factors, including temperature, light, $\mathrm{pH}$, medium composition, and plant growth regulators (Zhou et al., 2011; Tian, 2015). Hairy root cultures from many plant species have been widely studied for the production of secondary metabolites useful in pharmaceuticals, cosmetics, and food additives (Srivastava and Srivastava, 2007; Ludwig-Müller et al., 2014; Maschke et al., 2015). To our knowledge, glucosinolate production by hairy root cultures of kale has never been reported. Here, we describe hairy root induction and culture of kale, transformed with Agrobacterium rhizogenes, for the production of glucosinolates. In this study, we evaluated the effects of various growth media and three types of auxins on glucosinolate production in the hairy root cultures of kale by using high-performance liquid chromatography (HPLC) and electrospray ionization- mass spectrometry (ESI-MS).

\section{MATERIALS AND METHODS}

\section{Plant materials}

Green and red kale (Brassica oleracea var. acephala) seeds were purchased from Asia Seeds Ltd. (Seoul, Korea) and stored at $4^{\circ} \mathrm{C}$. The seeds were surface-sterilized with $70 \%(\mathrm{v} / \mathrm{v})$ ethanol for $30 \mathrm{~s}$ and $2 \%(\mathrm{v} / \mathrm{v})$ sodium hypochlorite solution for $10 \mathrm{~min}$, then rinsed three times in sterilized water. Five seeds were placed on $25 \mathrm{~mL}$ of agar-solidified culture medium in Petri dishes $(100 \times 15 \mathrm{~mm})$. The basal medium consisted of MS (Murashige and Skoog, 1962)salt and vitamin medium solidified with $0.7 \%$ (w/v) agar. The MS salt and vitamin medium was adjusted to $\mathrm{pH} 5.8$ before adding the agar and was then sterilized by autoclaving at $121^{\circ} \mathrm{C}$ for $20 \mathrm{~min}$. The seeds were germinated after 1 weeks culture in a growth chamber approximately $70 \%$ humidity at $25^{\circ} \mathrm{C}$ under standard cool white fluorescent tubes with a flux rate of $35 \mu \mathrm{mol} \mathrm{s} \mathrm{m}^{-2}$ and a $16-\mathrm{h}$ photoperiod.

\section{Establishment of hairy roots}

Hairy root cultures of green and red kale were established and maintained as previously described by Kim et al., 2013 b. In brief, hairy roots from green and red kale were subcultured on fresh agar-solidified MS medium and then transferred to MS liquid culture medium for experiments. The MS basal medium contained salts, vitamins, and $30 \mathrm{~g} \mathrm{~L}^{-1}$ sucrose. The $\mathrm{pH}$ of the medium was adjusted to 5.8 and the medium was then autoclaved for $20 \mathrm{~min}$. Hairy root cultures were maintained at $25^{\circ} \mathrm{C}$ on a gyratory shaker $(100 \mathrm{rpm})$ in a growth chamber with a 16-h photoperiod and cool white fluorescent lights (flux rate of $35 \mathrm{~mol} \mathrm{~s}^{-1} \mathrm{~m}^{-2}$ ). Three flasks were used for each culture and experiments were performed in duplicate.

\section{Optimisation of culture conditions Media}

For the selection of optimal medium conditions for hairy root culture and glucosinolates biosynthesis, the effects of half and full strength of B5, MS and SH media were tested, using the general procedures cited above and using a single factor experimental design.

\section{Auxin}

In an independent experiment from the one above, different concentrations $(0.1,0.5$ and $1.0 \mathrm{mg} / \mathrm{L})$ of the indole-3-acetic acid (IAA), indole-3-butyric acid (IBA) and 1-naphthaleneacetic acid (NAA) were added to the MS culture media to test their ability to promote hairy root growth and the biosynthesis of glucosinolates. Auxin (IAA, IBA and NAA) was purchased from Sigma-Aldrich (Milwaukee, WI, USA). The experiment was conducted using a single factor design. For both experiments, after 15 days in culture, hairy roots were harvested and the dry weight and the glucosinolates contents were determined. Three flasks were used for each culture condition, and experiments were performed in duplicate.

\section{Extraction of desulfoglucosinolates (DS-GSLs) and HPLC analysis}

Desulfoglucosinolates (DS-GSLs) were extracted using a slight modification of the procedures reported in a previous study (Kim et al., 2007). Briefly, crude GSLs were extracted from $100 \mathrm{mg}$ of freeze-dried powder of hairy 
root culture of kale by boiling in $1.5 \mathrm{~mL} 70 \%(\mathrm{v} / \mathrm{v}) \mathrm{MeOH}$ at $70^{\circ} \mathrm{C}$ for 5 min using a water bath. After centrifugation at $12,000 \mathrm{rpm}$ and $4^{\circ} \mathrm{C}$ for $10 \mathrm{~min}$ in a microcentrifuge (MICRO 17R; Hanil BioMed Inc., Incheon, Korea), the supernatant was collected in a 5 -mL test tube, and the residue was re-extracted twice as described above. The combined supernatants were used as the crude GSL extract. Desulfation of the crude GSL extracts was performed using a DEAE Sephadex A-25 anion exchange column, which was prepared by adding a slurry of DEAE-Sephadex A-25 that had been previously activated with $0.5 \mathrm{M}$ sodium acetate. The crude GSL extracts were loaded onto a pre-equilibrated column. After the column was washed ( $\times 3$ times) with $1 \mathrm{~mL}$ ultra-pure water to remove cations and neutral ions, aryl sulfatase (EC 3.1.6.1, type H-1 from Helix pomatia; $75 \mu \mathrm{L}$ ) was loaded onto each column. After being subject to the desulfation reaction overnight (16 h) at room temperature, the desulfated GSLs were eluted with $0.5 \mathrm{~mL}$ ultra-pure water $(\times 3$ times). The eluates were filtered through a $0.45-\mu \mathrm{m}$ Teflon PTFE syringe filter and immediately analyzed using HPLC or stored at $4^{\circ} \mathrm{C}$ until chemical analysis.

The DS-GSLs were separated on a reversed-phase Inertsil ODS-3 column $(150 \times 3.0 \mathrm{~mm}$ ID; $3-\mu \mathrm{m}$ particle size; GL Sciences, Tokyo, Japan) using an E-type cartridge guard column $(10 \times 3.0 \mathrm{~mm}$ ID, $5-\mu \mathrm{m}$ particle size $)$ and an Agilent Technologies 1260 series HPLC system (Palo Alto, CA, USA). The column oven temperature and detection wavelength were set at $40^{\circ} \mathrm{C}$ and $227 \mathrm{~nm}$, respectively, and the flow rate was $0.4 \mathrm{~mL} \mathrm{~min}^{-1}$. The mobile phase consisted of ultrapure water (solvent $\mathrm{A}$ ) and $\mathrm{CH}_{3} \mathrm{CN}$ (solvent $\mathrm{B}$ ). The gradient program was as follows: $0 \mathrm{~min}, 0 \% \mathrm{~B} ; 0-2 \mathrm{~min}$, 0\% B; 2-7 min, 10\% B; 7-16 min, 31\% B; 16-19 min, 31\% B; 19-21 min, $0 \% \mathrm{~B} ; 21-27 \mathrm{~min}, 0 \% \mathrm{~B}$ (total $27 \mathrm{~min}$ ). The individual GSLs were quantified according to their HPLC area and response factor by comparing with those of an external standard, $5 \mathrm{~mL}$ of sinigrin solution $\left(0.1 \mathrm{mg} \mathrm{mL}^{-1}\right)$, which was subjected to the same extraction process (Kim et al., 2007).

\section{Liquid chromatography-electrospray ionization-mass spectrometry (LC/ESI-MS) analysis for the quantitation of DS-GSLs.}

The MS data were acquired using an ESI-mass spectrometer with an API 4000 Q TRAP system (Applied Biosystems, Foster City, CA, USA) in positive ion mode $\left([\mathrm{M}+\mathrm{H}]^{+}\right)$, equipped with an Agilent 1200 series HPLC. The analytical conditions for MS were as follows: ion spray voltage: $5.5 \mathrm{kV}$; curtain gas: 20 psi, nebulizing gas: 50 psi, and heating gas: 50 psi high purity nitrogen $\left(\mathrm{N}_{2}\right)$; heating gas temperature: $550^{\circ} \mathrm{C}$; declustering potential: $100 \mathrm{~V}$; entrance potential: $10 \mathrm{~V}$; and spectral scanning range: $\mathrm{m} / \mathrm{z} 100-800$ (scan time, $4.8 \mathrm{~s}$ ).

\section{Statistical analysis}

All results are expressed as the mean of three biological replicates. Three subsamples were randomly generated from each harvested green and red kale genotype and then separate extractions were conducted on each replicate sample. Data were subjected to an analysis of variance (ANOVA) with sums of squares partitioned to reflect trial effects using SAS Software (release 9.2; SAS Institute Inc., Cary, NC, USA), and means were separated via Duncan's Multiple Range Test $(\mathrm{P}<0.05)$.

\section{RESULTS AND DISCUSSION}

\section{Glucosinolates biosynthesis in response to growth media}

The analysis of the hairy root cultures of kale (Brassica oleracea var. acephala) yielded four glucosinolates: 4-hydroxyglucobrassicin, glucobrassicin, 4-methoxy glucobrassicin, and neoglucobrassicin by HPLC and LC/ESI-MS/MS. The content of glucosinolates (Table 1) varied greatly according to the growth medium. None of the media resulted in the accumulation of the highest amounts of all types of glucosinolates. Of the six variations of media used, full-strength $\mathrm{B} 5$ resulted in the highest accumulation of total glucosinolates, followed by full-strength $\mathrm{SH}$, full-strength MS, half-strength B5, and half-strength SH. The lowest quantity of glucosinolates was accumulated using half-strength MS medium. Of the four glucosinolates, the accumulation of glucobrassicin was very high irrespective of the growth medium used. The glucobrassicin content in kale hairy root cultures ranged from 3.55 to $13.85 \mu \mathrm{mol} \mathrm{g}{ }^{-1} \mathrm{DW}$ in the different growth media. The glucobrassicin content was 3.9, 1.82, $1.81,1.62$, and 1.49 fold higher in $\mathrm{B} 5$ media than in $1 / 2 \mathrm{MS}$, $1 / 2 \mathrm{SH}, 1 / 2 \mathrm{~B} 5$, MS, and $\mathrm{SH}$, respectively. The second highest accumulated glucosinolate was 4-methoxyglucobrassicin. The content of 4-methoxyglucobrassicin ranged from 5.41 to $8.30 \mu \mathrm{mol} \mathrm{g}^{-1} \mathrm{DW}$ in response to the various types of growth media used in this study. Murashige-Skoog (MS) medium resulted in the highest accumulation of 4-methoxyglucobrassicin, which was $1.53,1.49,1.45$, 1.26 , and 1.15 -fold higher than those of $1 / 2 \mathrm{~B} 5, \mathrm{~B} 5$, $1 / 2 \mathrm{MS}, 1 / 2 \mathrm{SH}$, and $\mathrm{SH}$ media, respectively. The content of neoglucobrassicin ranged from 0.60 to $2.96 \mu \mathrm{mol} \mathrm{g}^{-1} \mathrm{DW}$ in response to the growth media used in this study. Halfstrength B5 medium supported the highest content of this compound, which was $4.93,4.17,4.10,2.33$, and 1.38 -fold higher than in MS, $1 / 2 \mathrm{MS}, \mathrm{SH}, 1 / 2 \mathrm{SH}$, and B5, respectively. The content of 4-hydroxyglucobrassicin was also influenced by the application of different media, with accumulated values of this glucosinolate ranging from 0.43 to $2.87 \mu \mathrm{mol} \mathrm{g}{ }^{-1} \mathrm{DW}$ in response to the growth media used. Exposure to $\mathrm{SH}$ medium resulted in the highest 
content of this compound, yielding 6.68-, 4.28-, 3.68-, 3.12 -, and 1.2-fold higher concentrations than those of $1 / 2 \mathrm{~B} 5, \mathrm{~B} 5,1 / 2 \mathrm{SH}, 1 / 2 \mathrm{MS}$, and MS, respectively.

\section{Glucosinolate biosynthesis in response to auxin}

The variation in glucosinolate content in response to different concentrations of auxin in the hairy root cultures was also investigated. Four different glucosinolates (4-hydroxyglucobrassicin, glucobrassicin, 4-methoxyglucobrassicin, and neoglucobrassicin) were detected in the hairy root cultures of kale using HPLC and LC/ESI-MS analyses (Table 2). The total and individual levels of glucosinolates in the hairy root cultures of kale were all influenced by auxin treatments, with the exception of glucobrassicin. In general, the level of glucosinolate content decreased with increasing concentrations of auxins. The total and individual levels of glucobrassicin did not vary among the auxin treatments (Table 2). The content of total glucosinolates ranged from 6.14 to $11.25 \mu \mathrm{mol} \mathrm{g}{ }^{-1} \mathrm{DW}$ among the auxin treatments. Treatment with the auxin indole-3-butyric acid (IBA) $0.1 \mathrm{mg} / \mathrm{mL}$ supported the highest total glucosinolate concentration, measuring 1.83 times higher than that of the lowest concentration, which was observed as a result of treatment with naphthalene acetic acid (NAA) $1.0 \mathrm{mg} / \mathrm{mL}$ treatment. Of the four glucosinolates, glucobrassicin and 4-methoxyglucobrassicin contents were considerably higher when treated with auxins. The content of 4-methoxyglucobrassicin in hairy root cultures ranged from 3.53 to $6.50 \mu \mathrm{mol} \mathrm{g}^{-1} \mathrm{DW}$ among the auxin treatments. Treatment with the auxin IBA $0.1 \mathrm{mg} / \mathrm{mL}$ promoted the highest 4-methoxyglucobrassicin accumulation in the hairy root culture of kale, yielding a concentration 1.84 times higher than NAA $1.0 \mathrm{mg} / \mathrm{mL}$, which accumulated the lowest amount. Treatment with the auxin indole- 3 -acetic acid (IAA) $0.1 \mathrm{mg} / \mathrm{mL}$ resulted in the second highest 4-methoxyglucobrassicin concentration in the hairy root culture of kale. The content of 4-hydroxyglucobrassicin ranged from 0.16 to $1.24 \mu \mathrm{mol} \mathrm{g}^{-1} \mathrm{DW}$ among the auxin treatments. Treatment with IAA $0.1 \mathrm{mg} / \mathrm{mL}$ resulted in the highest amount of 4-hydroxyglucobrassicin, measuring 7.75, 4.13, and 1.90 times higher than that accumulated in response to NAA $1.0 \mathrm{mg} / \mathrm{mL}$, IBA $1.0 \mathrm{mg} / \mathrm{mL}$, and IAA $1.0 \mathrm{mg} / \mathrm{mL}$ treatment, respectively. Neoglucobrassicin content ranged from 0.43 to $1.06 \mu \mathrm{mol} \mathrm{g}^{-1} \mathrm{DW}$ among the auxin treatments. Treatment with IAA $0.1 \mathrm{mg} / \mathrm{mL}$ resulted in the highest amount of neoglucobrassicin, measuring 2.46 times higher than that of auxin treatments NAA $0.1 \mathrm{mg} / \mathrm{mL}$ and NAA $1.0 \mathrm{mg} / \mathrm{mL}$, which resulted in the lowest concentration of neoglucobrassicin.

In the present study, full-strength B5 resulted in the highest accumulation of total glucosinolates, followed by

Table 1: Effects of media on glucosinolate biosynthesis in hairy root cultures of kale (Brassica oleracea var. acephala)

\begin{tabular}{|c|c|c|c|c|c|}
\hline \multirow[t]{2}{*}{ Media } & \multicolumn{5}{|c|}{ Glucosinolates ( $\mu \mathrm{mol} / \mathrm{g}$ dry weight) } \\
\hline & $\begin{array}{l}\text { 4-hydroxy } \\
\text { glucobrassicin }\end{array}$ & Glucobrassicin & $\begin{array}{l}\text { 4-Methoxy } \\
\text { glucobrassicin }\end{array}$ & $\begin{array}{l}\text { Neogluco } \\
\text { brassicin }\end{array}$ & Total \\
\hline $1 / 2 \mathrm{MS}$ & $0.92 \pm 0.23$ & $3.55 \pm 0.01$ & $5.72 \pm 0.23$ & $0.71 \pm 0.01$ & $10.90 \pm 0.01$ \\
\hline MS & $2.40 \pm 0.55$ & $8.54 \pm 0.21$ & $8.30 \pm 0.29$ & $0.60 \pm 0.02$ & $19.85 \pm 0.69$ \\
\hline $1 / 2 \mathrm{SH}$ & $0.78 \pm 0.29$ & $7.62 \pm 0.08$ & $6.58 \pm 0.21$ & $1.27 \pm 0.09$ & $16.25 \pm 0.36$ \\
\hline $\mathrm{SH}$ & $2.87 \pm 0.80$ & $9.30 \pm 0.45$ & $7.23 \pm 0.50$ & $0.73 \pm 0.16$ & $20.14 \pm 1.49$ \\
\hline 1/2B5 & $0.43 \pm 0.12$ & $7.67 \pm 0.23$ & $5.41 \pm 0.36$ & $2.96 \pm 0.01$ & $16.47 \pm 0.63$ \\
\hline B5 & $0.67 \pm 0.43$ & $13.85 \pm 0.72$ & $5.58 \pm 0.45$ & $2.14 \pm 0.05$ & $22.24 \pm 1.58$ \\
\hline
\end{tabular}

The data are expressed as mean \pm SD with three replications in each experiment. B5, Gamborg B5 medium; 1/2 B5, half strength of B5; MS, Murashige and Skoog medium; $1 / 2 \mathrm{MS}$, half strength of MS; $\mathrm{SH}$, Schenk and Hildebrandt medium; $1 / 2 \mathrm{SH}$, half strength of $\mathrm{SH}$

Table 2: Effects of auxin on glucosinolate biosynthesis in hairy root cultures of kale (Brassica oleracea var. acephala)

\begin{tabular}{|c|c|c|c|c|c|}
\hline \multirow{2}{*}{$\begin{array}{l}\text { Auxin } \\
\text { (mg/l) }\end{array}$} & \multicolumn{5}{|c|}{ Glucosinolates ( $\mu \mathrm{mol} / \mathrm{g}$ dry weight) } \\
\hline & $\begin{array}{c}\text { 4-hydroxy } \\
\text { glucobrassicin }\end{array}$ & Glucobrassicin & $\begin{array}{c}\text { 4-Methoxy } \\
\text { glucobrassicin }\end{array}$ & $\begin{array}{l}\text { Neogluco } \\
\text { brassicin }\end{array}$ & Total \\
\hline Control & $0.92 \pm 0.23$ & $3.55 \pm 0.01$ & $5.72 \pm 0.23$ & $0.71 \pm 0.01$ & $10.90 \pm 0.01$ \\
\hline IAA 0.1 & $1.24 \pm 0.31$ & $3.34 \pm 0.23$ & $4.97 \pm 0.28$ & $1.06 \pm 0.01$ & $10.61 \pm 0.83$ \\
\hline IAA 0.5 & $0.62 \pm 0.11$ & $2.11 \pm 0.00$ & $5.76 \pm 0.15$ & $0.48 \pm 0.05$ & $8.98 \pm 0.08$ \\
\hline IAA 1.0 & $0.65 \pm 0.19$ & $2.47 \pm 0.11$ & $4.54 \pm 0.04$ & $0.64 \pm 0.00$ & $8.30 \pm 0.34$ \\
\hline IBA 0.1 & $0.83 \pm 0.59$ & $2.90 \pm 0.35$ & $6.50 \pm 0.94$ & $1.03 \pm 0.04$ & $11.25 \pm 1.92$ \\
\hline IBA 0.5 & $0.34 \pm 0.17$ & $1.99 \pm 0.00$ & $4.44 \pm 0.00$ & $0.54 \pm 0.01$ & $7.31 \pm 0.18$ \\
\hline IBA 1.0 & $0.30 \pm 0.12$ & $2.07 \pm 0.10$ & $4.90 \pm 0.25$ & $0.52 \pm 0.05$ & $7.80 \pm 0.52$ \\
\hline NAA 0.1 & $0.31 \pm 0.01$ & $1.98 \pm 0.02$ & $3.88 \pm 0.00$ & $0.43 \pm 0.00$ & $6.60 \pm 0.01$ \\
\hline NAA 0.5 & $0.30 \pm 0.18$ & $2.14 \pm 0.19$ & $4.92 \pm 0.39$ & $0.58 \pm 0.08$ & $7.94 \pm 0.84$ \\
\hline NAA 1.0 & $0.16 \pm 0.00$ & $2.00 \pm 0.30$ & $3.53 \pm 0.51$ & $0.44 \pm 0.09$ & $6.14 \pm 0.89$ \\
\hline
\end{tabular}

The data are expressed as mean \pm SD with three replications in each experiment. IAA, indole-3-acetic acid; IBA, indole-3-butyric acid; NAA, 1-naphthaleneacetic acid 
full-strength $\mathrm{SH}$, full-strength MS, half-strength $\mathrm{B}$, and half-strength SH. The lowest amount of glucosinolates was accumulated in the half-strength MS media treatment $\left(10.90 \mu \mathrm{mol} \mathrm{g}^{-1} \mathrm{DW}\right)$. These data are in agreement with those from an investigation of glucosinolate biosynthesis in the hairy root cultures of broccoli (Kim et al., 2013b), where growth media was shown to significantly influence growth and glucosinolate content. It is well known that GSL content in plants varies widely according to environmental factors, such as agronomic management, climatic conditions, and mineral nutrient availability, as well as location within the plant, developmental stage, and plant variety (Brown et al., 2002; Vallejo et al., 2003; Kumar and Andy, 2012). Neoglucobrassicin is usually a minor GSL in broccoli, with a content of less than $10 \mu \mathrm{mol} \mathrm{g}^{-1} \mathrm{DW}$ in Portuguese broccoli and $1 \mu \mathrm{mol} \mathrm{g}{ }^{-1} \mathrm{DW}$ in Thai broccoli (Rosa and Rodrigues, 2001; Chuanphongpanich et al., 2006). In this study, we found similar results for neoglucobrassicin levels, which ranged from 0.60 to $2.96 \mu \mathrm{mol} \mathrm{g}^{-1} \mathrm{DW}$. In contrast, glucoraphanin is usually reported as a major glucosinolate in broccoli, even though its content varies widely between cultivars (West et al., 2004; Chuanphongpanich et al., 2006). In this study, the level of glucoraphanin was very low and varied from 1.7 to $3.9 \mu \mathrm{mol} \mathrm{g}{ }^{-1} \mathrm{DW}$ in the different media treatments.

The accumulation of secondary metabolites, such as glucosinolates, in any part of mother or transformed plants, is largely dependent on their sources of origin; however, their accumulation can be affected by treatment with phytohormones and elicitors, as well as by environmental factors. Auxins are phytohormones that are known to play important roles in plant growth and root development, including the modulation of secondary metabolites. However, the effects of auxins can vary across different plant species. In this study, auxins were shown to play a vital role in the accumulation of glucosinolates in the hairy root cultures of kale. Glucosinolate accumulation in the hairy root cultures of kale was found to be higher at low concentrations of auxins, whereas increasing concentration of auxins resulted in decreases in glucosinolate in most cases. Auxin treatments resulted in the accumulation of higher amounts of glucosinolate in the hairy root cultures of kale. Of the auxin treatments, IAA and IBA at $0.1 \mathrm{mg} / \mathrm{mL}$ led to the highest accumulation of most glucosinolates in this study. Our previous findings that low concentrations of IAA led to the highest accumulation of glucosinolates in the hairy root cultures of broccoli (Kim et al., 2013b). are agreement with the findings of the current study, where lower concentrations of auxins resulted in higher concentrations of glucosinolates. Another study by Kim et al., 2013a. reported that five different glucosinolates (glucoerucin, glucobrassicin, 4-methoxyglucobrassicin, gluconasturtiin, and neoglucobrassicin) were detected in the hairy root cultures of Chinese cabbage, and that glucosinolate accumulation was higher at lower concentrations of auxins.

Hairy root cultures could be a valuable alternative approach for the production of glucosinolate compounds from kale. Our study results suggested that media treatments, notably full-strength B5 and $\mathrm{SH}$ media, and auxin treatments, notably IAA and IBA at lower concentrations $(0.1 \mathrm{mg} / \mathrm{mL})$, resulted in higher concentrations of glucosinolates in the hairy roots of kale. Hairy root cultures might be a valuable alternative approach for the production of glucosinolate compounds from kale. Our current laboratory efforts are aimed at further improving glucosinolate compound production in the hairy root cultures of kale.

\section{ACKNOWLEDGEMENTS}

This study was supported by the Regional Innovation Center for Dental Science \& Engineering, Chosun University, Gwangju, Korea (B0008940).

\section{Author's contribution}

S.U. Park and J.K. Kim designed the experiments, analyzed the data, and wrote the manuscript. S.Y. Lee and S.J. Bong wrote the manuscript, performed the experiments, and analyzed the data. All authors read and approved the manuscript.

\section{REFERENCES}

Al-Gendy, A. A., O. D. El-Gindi, A. S. Hafez and A. M. Ateya. 2010. Glucosinolates, volatile constituents and biological activities of Erysimum corinthium Boiss. (Brassicaceae). Food Chem. 118: 519-524.

Baenas, N., D. A. Moreno and C. García-Viguera. 2012. Selecting sprouts of brassicaceae for optimum phytochemical composition. J. Agric. Food Chem. 60: 11409-11420.

Björkman, M., I. Klingen, A. N. Birch, A. M. Bones, T. J. Bruce, T. J. Johansen, R. Meadow, J. Mølmann, R. Seljåsen, L. E. Smart and D. Stewart. 2011. Phytochemicals of Brassicaceae in plant protection and human health-influences of climate, environment and agronomic practice. Phytochemistry. 72: 538-556.

Brown, A. F., G. G. Yousef, E. H. Jeffery, B. P. Klein, M. A. Wallig, M. M. Kushad and J. A. Juvik. 2002. Glucosinolate profiles in broccoli: Variation in levels and implications in breeding for cancer chemoprotection. J. Am. Soc. Hortic. Sci. 127: 807-813.

Chuanphongpanich, S., S. Phanichphant, D. Bhuddasukh, M. Suttajit and B. Sirithunyalug. 2006. Bioactive glucosinolates and antioxidant properties of broccoli seeds cultivated in Thailand. Songklanakarin J. Sci. Technol. 28: 55-61.

Clarke, D. B. 2010. Glucosinolates, structures and analysis in food. Anal. Method. 2: 310-325.

Conaway, C. C., Y. M. Yang and F. L. Chung. 2002. Isothiocyanates as Cancer chemopreventive agents: Their biological activities and metabolism in rodents and humans. Curr. Drug Metabol. 3: 233-255.

De Nicola, G. R., M. Bagatta, E. Pagnotta, D. Angelino, L. Gennari, 
P. Ninfali, P. Rollin and R. Iori. 2013. Comparison of bioactive phytochemical content and release of isothiocyanates in selected brassica sprouts. Food Chem. 141: 297-303.

Groenbaek, M., S. Jensen, S. Neugart, M. Schreiner, U. Kidmose and H. L. Kristensen. 2016. Nitrogen split dose fertilization, plant age and frost effects on phytochemical content and sensory properties of curly kale (Brassica oleracea L. var. sabellica). Food Chem. 197: 530-538.

Herr, I. and M. W. Büchler. 2010. Dietary constituents of broccoli and other cruciferous vegetables: implications for prevention and therapy of cancer. Cancer Treat. Rev. 36: 377-383.

Jørgensen, M. E., H. H. Nour-Eldin and B. A. Halkier. 2015. Transport of defense compounds from source to sink: lessons learned from glucosinolates. Trends Plant Sci. 20: 508-514.

Kim, S. J., C. Kawaharada, S. Jin, M. Hashimoto, G. Ishii and H. Yamauchi. 2007. Structural elucidation of 4-(cystein-S-yl) butyl glucosinolate from the leaves of Eruca sativa. Biosci. Biotechnol. Biochem. 71: 114-121.

Kim, S. Y., S. Yoon, S. M. Kwon, K. S. Park and Y. C. Kim. 2008. Kale juice improves coronary artery disease risk factors in hypercholesterolemic men. Biomed. Environ. Sci. 21: 91-97.

Kim, H. H., D. Y. Kwon, H. Bae, S. J. Kim, Y. B. Kim, M. R. Uddin and S. U. Park. 2013a. Influence of auxins on glucosinolatebiosynthesis in hairy root cultures of broccoli (Brassica oleracea var. italica). Asian J. Chem. 25: 6099-6101.

Kim, S. J., W. T. Park, M. R. Uddin, Y. B. Kim, S. Y. Nam, K. H. Jho and S. U. Park. 2013b. Glucosinolate biosynthesis in hairy root cultures of broccoli (Brassica oleracea var. italica). Nat. Prod. Commun. 8: 217-220.

Krzyzanowska, J., A. Czubacka and W. Oleszek. 2011. Dietary phytochemicals and human health. Adv. Exp. Med. Biol. 698: 74-98.

Kumar, S. and A. Andy. 2012. A health promoting bioactive phytochemicals from Brassica. Int. Food Res. J. 19: 59-66.

Ludwig-Müller, J., L. Jahn, A. Lippert, J. Püschel and A. Walter. 2014. Improvement of hairy root cultures and plants by changing biosynthetic pathways leading to pharmaceutical metabolites: Strategies and applications. Biotechnol. Adv. 32: 1168-1179.

Maschke, R. W., K. Geipel and T. Bley. 2015. Modeling of plant in vitro cultures: Overview and estimation of biotechnological processes. Biotechnol. Bioeng. 112: 1-12.
Migliozzi, M., D. Thavarajah, P. Thavarajah and P. Smith. 2015. Lentil and kale: Complementary nutrient-rich whole food sources to combat micro nutrient and calorie malnutrition. Nutrients. 7: 9285-9298.

Park, S., M. V. Arasu, M. K. Lee, J. H. Chun, J. M. Seo, N. A. AlDhabi and S. J. Kim. 2014. Analysis and metabolite profiling of glucosinolates, anthocyanins and free amino acids in inbred lines of green and red cabbage (Brassica oleracea L.). Food Sci. Technol. 58: 203-213.

Rosa, E. A. S. and A. S. Rodrigues. 2001. Total and individual glucosinolate content in 11 broccoli cultivars grown in early and late seasons. Hort. Sci. 36: 56-59.

Sikora, E. and I. Bodziarczyk. 2012. Composition and antioxidant activity of kale (Brassica oleracea L. var. acephala) raw and cooked. Acta. Sci. Pol. Technol. Aliment. 11: 239-248.

Srivastava, S. and A. K. Srivastava. 2007. Hairy root culture for mass-production of high-value secondary metabolites. Crit. Rev. Biotechnol. 27: 29-43.

Tian, L. 2015. Using hairy roots for production of valuable plant secondary metabolites. Adv. Biochem. Eng. Biotechnol. 149: 275-324.

Vallejo, F., F. A. Tomas-Barberán, A. Gonzalez Benavente-García and C. García-Viguera. 2003. Total and individual glucosinolate contents in inflorescences of eight broccoli cultivars grown under various climatic and fertilization conditions. J. Sci. Food Agric. 83: 307-313.

Walsh, R. P., H. Bartlett and F. Eperjesi. 2015. Variation in carotenoid content of kale and other vegetables: A review of pre- and postharvest effects. J. Agric. Food Chem. 63: 9677-9682.

West, L. G., K. A. Meyer, B. A. Balch, F. J. Rossi, R. M. Schultz and G. W. Haas. 2004. Glucoraphanin and 4-hydroxyglucobrassicin contents in seeds of 59 cultivars of broccoli, raab, kohlrabi, radish, cauliflower, Brussels sprouts, kale, and cabbage. J. Agric. Food Chem. 52: 916-926.

Zhi-Bi, H. and D. Min. 2006. Hairy root and its application in plant genetic engineering J. Integr. Plant Biol. 48: 121-127.

Zhou, M. L., X. M. Zhu, J. R. Shao, Y. X. Tang and Y. M. Wu. 2011. Production and metabolic engineering of bioactive substances in plant hairy root culture. Appl. Microbiol. Biotechnol. 90: 1229-1239. 